\title{
A reinvenção de si no mundo da rua: Trajetos e narrativas de quem nela vive
}

Maria Teresa Nobre

Irlys Alencar Firmo Barreira

\section{RESUMO}

0 artigo descreve e analisa modos de vida de pessoas que vivem nas ruas, tomando como referência etnográfica duas histórias registradas em Fortaleza e Lisboa, das quais nos aproximamos fazendo uso da observação participante e da observação itinerante. As narrativas sobre a vida no mundo da rua apontam a multiplicidade, a diversidade e a provisoriedade como marcas sobre as quais se assentam a vida de nômades urbanos contemporâneos. As muitas maneiras de viver o cotidiano, observadas neste estudo, apontam a reinvenção de si e do mundo da rua através da criação de novos territórios materiais e existenciais. Reinvenção que ultrapassa a fronteira exclusiva da carência e imagem da vitimização ou da culpabilização como polos em torno dos quais se assentam as representações sobre pessoas em situação de rua e sem abrigo, nas duas cidades pesquisadas.

Palavras-chave: pessoas em situação de rua; etnografia; narrativa.

\section{ABSTRACT}

\section{The reinvention of self in the world of the street: Paths and narratives of who lives in it}

The article describes and analyses the lifestyle of people living in the streets, starting from two stories used as ethnographic references, through participant and itinerant observations in the cities of Fortaleza and Lisbon. The narratives about life in the "world of the streets", point out the multiplicity, diversity, and temporality as marks of the lives of contemporary urban nomads. The diverse ways of living observed in this study point out the reinvention of themselves and the street's world through the creation of new material and existential territories. Reinvention that surpasses the exclusive frontier of need and image victimization and blaming that are often used as poles of representation of homeless in two surveyed cities.

Keywords: homeless; ethnography; narrative.

Como pessoas em condições extremas de destituição de bens materiais e simbólicos inventam a vida de cada dia, fazendo da rua morada ou território de existência? A despeito da pobreza e vulnerabilidade comuns a todos nessa condição, o "mundo da rua" oferece às pessoas que nele ou dele vivem a possibilidade de ampliação de territórios existenciais? Essas questões foram suscitadas por ocasião de uma pesquisa etnográfica realizada em Fortaleza e Lisboa, entre os anos de 2016 e 2017¹. O objetivo principal da investigação foi conhecer trajetórias urbanas e o que poderia ser nomeado de "práticas de resistência" de pessoas que vivem na rua. Trata-se de indivíduos designados pela nomenclatura das políticas públicas como estando em situação de rua/sem abrigo, que desenvolvem ações táticas e estratégicas para enfrentarem ambientes inóspitos estando submetidos permanentemente ao poder disciplinador dos espaços urbanos (Foucault, 2000).

Em termos objetivos, a população em situação de rua é designada, do ponto de vista da política pública brasileira, como um contingente heterogêneo, formado por pessoas que têm

\section{Sobre os Autores}

M. T. N.

orcid.org/0000-0002-5085-4296

Universidade Federal do Rio

Grande do Norte (UFRN) - Natal, RN

teresa-nobre@uol.com.br

\section{A. F. B.}

orcid.org/0000-0002-3964-946X Universidade Federal do Ceará (UFC) - Fortaleza, CE

irlys.firmo@gmail.com

\section{Direitos Autorais}

Este é um artigo de acesso aberto e pode ser reproduzido livremente, distribuído, transmitido ou modificado, por qualquer pessoa desde que usado sem fins comerciais. 0 trabalho é disponibilizado sob a licença Creative Commons CCBY-NC.

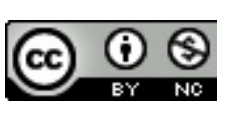


em comum a pobreza extrema, vínculos familiares rompidos ou frágeis, sem moradia, que habitam logradouros públicos ou áreas degradadas ou pernoitam em instituições públicas e filantrópicas voltadas para este fim, de modo permanente ou temporário (Brasil, 2009).

Em Portugal, utiliza-se para a mesma situação o termo "pessoa sem abrigo" para designar aquela que, "independentemente da sua nacionalidade, idade, sexo, condição socioeconómica e de saúde física e mental, se encontra sem teto, a viver no espaço público, abrigo de emergência ou local precário; ou sem casa, encontrando-se em alojamento temporário destinado para o efeito" (ENIPSA, 2009, p. 8).

Ambas apontam a carência como elemento central. Tratase de definição que opera no negativo, enfatizando, tanto a ausência de moradia segura, quanto a falta consequente de bens e da garantia de cidadania. O elenco de faltas e privações também define essas pessoas no senso comum: são carentes de cultura, educação, saberes cotidianos e responsabilidades. Em síntese: são vistos como aqueles que nada têm ou já perderam tudo.

A rua adquire, assim, o simbolismo da perda absoluta, da decrepitude - última escala do que seria o avesso da cidadania. Uma breve reflexão sobre o que pode ser denominado por mundo da rua torna-se importante para o desenvolvimento das questões que vem sendo analisadas.

A rua é uma categoria dotada de sentido polissêmico, tanto no plano das teorizações como no âmbito das categorias nativas, ou seja, aqueles presentes no próprio campo, que emanam da fala das pessoas quando se referem às suas práticas e seus modos de viver. Em oposição à casa, na acepção apropriada por DaMatta (2003), a rua supõe o lugar de impessoalidade, das leis que se aplicam aos desconhecidos e distantes de benefícios propiciados por relações pessoais. Os supostos negativos da rua povoam o senso comum, produzindo classificações e preconceitos dotados de performatividade. Ser colocado no "olho dar rua", ser da rua ou "cair na rua da amargura" são expressões que revelam o teor negativo embutido nas representações de um lugar que é fonte de muitas atribuições. A rua pode também ser pensada como a esfera na qual as opiniões públicas se produzem, no sentido emprestado por Habermas (1994), expressando-se algumas vezes em manifestações e protestos dotados de visibilidade.

No que se refere aos que usam a rua de modo não efêmero, fazendo desse lugar um abrigo e moradia, as discussões são dotadas de complexidade. As ruas não são apenas o lugar da destituição de bens de cidadania (moradia e trabalho), mas também lugar de inversão de usos convencionais. Trata-se de modos de apropriação dos espaços que são inventivos, pois desviantes de sua função original. As pessoas que vivem nas ruas constroem coletivos, inventam casas, resistem às intempéries do tempo, desafiam o mundo com sua miséria que é também a miséria do mundo (Bourdieu, 2012). As políticas sociais voltadas para retirar as pessoas que moram ou vivem nas ruas utilizam estratégias de suporte alimentar, médico e de higiene, com tentativas de trabalho e oferta de moradias alternando disciplina e/ou filantropia. Esses são, via de regra, projetos amplos e totalizantes que não observam a heterogeneidade dos estilos de vida, necessidades e desejos dessa população que não é uma categoria homogênea, variando conforme faixa etária, gênero, cor da pele ou capital familiar, capazes de agregar diferentes formas de vulnerabilidade.

Paradoxalmente, a rua abriga pessoas que nela ou dela vivem, sendo consolo para suas misérias e angústias, espaço para sua existência, como dizia o escritor João do Rio no início do século XX, em afirmações que reverberam atuais:

A rua tem alma! Ela é agasalhadora da miséria. Os desgraçados não se sentem de todo sem o auxílio dos deuses enquanto diante dos seus olhos uma rua abre para outra rua. A rua é o aplauso dos medíocres, dos infelizes, dos miseráveis da arte. (...) A rua é generosa. 0 crime, o delírio, a miséria, não os denuncia a ela. (...) A rua é a mais niveladora das obras humanas. (Rio, 2013, p. 20).

De fato, no percurso da pesquisa encontramos pessoas há mais de duas décadas vivendo nas ruas; outras, recémchegadas, estão nas ruas há poucos meses. No mundo da rua essas pessoas encontraram lugar, inventaram criativamente modos de vida ou acostumaram-se à prática de fazer, da rua, casa ou palco da sua existência. Outros, andarilhos, fazem da errância seu território existencial, abrigando-se nas ruas da cidade, sem pouso certo.

Dentre os muitos encontros mantidos com essas pessoas, destacamos duas histórias, a partir das quais é possível perceber, por sobre a ideia de carência e privação, a rua como potência.

Assim, a experiência da solidão, do sofrimento, do desamparo, das violências e das misérias que se tornam lastro comum dessas existências, surge como campo de novas aprendizagens inventivas, a partir do estranhamento e de problematizações acerca do que está dado como fixo, estável e previsível (Kastrup, 2001) e que se desestabiliza com a precariedade e desafios da vida no mundo da rua. 0 encontro com novos signos que produzem o estranhamento neste mundo desconhecido e hostil, interpela, interroga e desafia. Esse processo incita novas aprendizagens que podem se configurar como reinvenção de si, na medida em que produzem o novo, o imprevisível, o inesperado, nos modos de lidar com os outros e consigo. Este é um plano de 


\section{H NTERAC̄öEM ET. PSICOLOGIA}

"produção de subjetividade que não pode ser concebido sem o seu correlato, que é a invenção do mundo" (Kastrup, 2001, p. 21).

Trata-se, na esteira de Foucault, de pensar o sujeito como sendo historicamente constituído sobre uma base de poderes e saberes que lhes são exteriores (Foucault, 2000). Entretanto, é o próprio Foucault que, se opondo à agência absoluta do sujeito, pensa nas possibilidades de resistência: as práticas de si como capacidade de não submissão completa ao poder que pretende gerir a vida, sobretudo em momentos críticos do próprio pensamento (Foucault, 1985). Abrir-se-ia, portanto, um espaço de inflexão, tematizado como dobra nos dispositivos de poder e saber que conformam a vida dos indivíduos.

Nossa pretensão na pesquisa é a de pensar possíveis situações de criatividade e resistência, ainda sob inspiração foucaultiana, sem desconhecer sua crítica radical à noção de sujeito, visto de uma perspectiva autônoma, como se as suas práticas decorressem de escolhas subjetivas, não submetidas a injunções institucionais. Assim, não pretendemos, ao narrar os modos de vida das pessoas pesquisadas, enfatizar subjetividades individuais, interioridades, identidades psicológicas ou a centralidade do eu. Antes, colocamos em evidência modos pelos quais esses sujeitos objetivados a partir de práticas de poder/saber que incidem sobre seus corpos e suas vidas e, assim, os constituem, se reinventam e criam possibilidades na relação consigo e com o mundo da rua. O que destacamos nessas narrativas são as práticas sociais e não seus autores, enquanto indivíduos, pois, como lembra Michel de Certeau:

De um lado, a análise mostra antes que a relação (sempre social) determina seus termos, e não o inverso, e que cada individualidade é o lugar onde atua uma pluralidade incoerente (e muitas vezes contraditória) de suas determinações relacionais. De outro lado, e sobretudo, a questão tratada se refere a modos de operação ou esquemas de ação e não diretamente ao sujeito que é seu autor e seu veículo (Certeau, 2005, p. 37-38).

Desejando perceber a complexidade da questão convidamos os nossos leitores a fazer uma viagem pelo mundo da rua, com seus códigos, suas lógicas, suas regras, seus valores, a partir dos quais as pessoas se reinventam e reinventam a vida.

\section{UMA PESQUISA ITINERANTE}

Adotando a etnografia como método (Goldman, 2003; Magnani, 2009), as andanças pelas duas cidades configuraram a regra da observação participante e da observação itinerante, tendo em vista a aproximação com as pessoas e seus modos de vida na rua.

Em Fortaleza, foram definidos dois campos para a pesquisa: o acompanhamento de ações desenvolvidas em uma casa de apoio a pessoas que vivem nas/das ruas no centro da cidade, gerida por religiosos e leigos católicos, em parceria com duas universidades, e cinco praças no centro da cidade, usadas como local para dormir, trabalhar ou permanecer por alguns períodos do dia, sem nada fazer. A casa de apoio é aberta três vezes por semana, onde as pessoas podem tomar banho, lavar roupas, fazer uma pequena refeição e participar de rodas de conversa e grupos de discussão sobre temáticas pertinentes a esta população. $\mathrm{Na}$ ocasião, são discutidos problemas como carência da moradia, uso de drogas, rupturas com a família e desemprego. Fala-se também sobre amizade, alternativas para obter dinheiro, astúcias para driblar a fome e encontrar lugares para pernoitar fora dos albergues noturnos.

Nesta etapa do trabalho, nos inserimos no campo através da observação participante. Esta, como técnica fundamental da investigação etnográfica, se caracteriza por interações sociais intensas entre pesquisador e sujeito no campo, durante as quais experiências e atividades são compartilhadas. A observação ao vivo, as conversas informais, a entrevista etnográfica e outras fontes de dados levam o pesquisador a adquirir um conhecimento de membro do grupo que estuda (Lapassade, 2005, p. 70). Participando ativamente das atividades realizadas na casa de apoio, sobretudo como membro das rodas de conversa, foi possível o acompanhamento e registro desses encontros em diário de campo, identificando pessoas com potencialidade para conversar individualmente em encontros posteriores. Pessoas naturais de Fortaleza, do interior do estado e de outros estados brasileiros, levadas a viver nas ruas pelo desemprego, pelo uso abusivo da droga ou por violência familiar, e dois andarilhos de saudade que não suportaram a morte de pessoas queridas, foram nossos interlocutores no trabalho de campo, durante três meses.

Em Lisboa, iniciamos o trabalho de campo acompanhando um grupo de voluntários que distribui alimentos aos sem-abrigo todas as noites abrangendo praticamente todo o perímetro urbano da cidade. Usamos essa estratégia de imersão no campo, pois, sabendo bem das dificuldades na abordagem dessas pessoas no trabalho que realizamos no Brasil, reconhecíamos a necessidade de mediações na aproximação com os possíveis sujeitos. Através dessas voltas noturnas que também se configuraram como um trabalho de observação participante, encontramos cerca de duzentas pessoas sem abrigo, ao longo de quatro meses. Mapeamos pontos de concentração dessas pessoas na cidade e identificamos alguns com quem poderíamos 


\section{W'INTERACÃO EM ET. PSICOLOGIA}

voltar a conversar posteriormente, a partir de dois critérios: pessoas que pareciam adotar modos mais usuais de viver nas ruas, mantendo lugar fixo para pernoite e alimentação, por exemplo, e pessoas que diferiam dos padrões normativos referentes aos usos do espaço, do tempo, à reinvenção dos objetos e aos percursos urbanos. Três portugueses, duas romenas, um ucraniano e um moçambicano compuseram um mosaico de experiências muito singulares que expressam a problemática dos sem-abrigo em Portugal: imigrantes sem abrigo; sem abrigo imigrantes e portugueses sem abrigo.

Tanto em Lisboa quanto em Fortaleza, não foram realizadas entrevistas. As instituições que mediaram nossa inserção no campo foram informadas sobre a realização da pesquisa, tiveram acesso ao projeto e autorizaram a realização do trabalho de campo. Entretanto, os relatos e narrativas das pessoas que vivem nas ruas foram sempre espontâneos, sendo as falas registradas mnemonicamente sem o uso de gravador e depois escritas em diário de campo, - mais fielmente possível. Algumas vezes, códigos, expressões ou palavras-chave foram anotadas no caderno de campo, para ajudar o resgate da memória das narrativas. Isso também aconteceu com as caminhadas pela cidade, descritas a seguir, como recurso para aproximação dos modos de vida, das práticas cotidianas e da observação de fatos e circunstâncias no exato momento em que aconteciam, como é próprio da pesquisa etnográfica, na sua tradição de fazer pesquisa em situação (Pina-Cabral \& Durão, 2013).

Ao lado da observação participante, tanto em Fortaleza quanto em Lisboa, foram utilizados registros que podem ser denominados de observação itinerante. Esta consiste em caminhadas pela cidade, como uma maneira privilegiada de entrar em contato com o campo, numa aproximação mais sensorial, imagética e menos vinculada aos discursos dos sujeitos, como sugere Pais (2015). Trabalhar em determinados campos e com objetos marginais, do ponto de vista social e acadêmico, diz ele, implica a necessidade de "passar de uma lógica de demonstração para uma lógica de descoberta" (Pais, 2015, p. 4), e, neste sentido, outras metodologias se fazem necessárias. Trata-se de se deixar dirigir "mais pelos sentidos do que pelas pernas", em busca de estabelecer conexões entre o objetivo e o subjetivo, o particular e o global, o individual e o coletivo, transversalizando percursos e processos, a fim de perceber "aquilo que está na epiderme do cotidiano daqueles que habitam a cidade" (Pais, 2015, p. 5).

As caminhadas pela cidade foram uma ferramenta preciosa no trabalho de campo, para acessar modos de vida cotidiana dessas pessoas, quando passamos a fazer longos percursos a pé, em dias e horários diferentes nos lugares que escolhemos, ou mesmo sem destino demarcado a priori, em um exercício de procurar aguçar o olhar e apurar a escuta, priorizando algumas cenas, acontecimentos, eventos e conversas espontâneas, como é próprio da etnografia (Sato \& Souza, 2001; Goldman, 2003; Magnani, 2009). O trabalho teve como foco a observação situacional não interventiva aquela que não é centrada em metodologias de obtenção verbal de informação, mas que tem como foco uma situação ou evento social do qual o investigador participa sem interferir ou abdicar da condição de observador externo num encontro com o cotidiano como campo estruturado por sociabilidades (Pina-Cabral \& Durão, 2013, p. 4). Assim, pudemos perceber o desenrolar das práticas e acompanhar rotinas, nas quais capturamos aquilo que se repete sucessivamente e o que se inventa, a cada dia. Polaridades entre permanências e mudanças, que tornam a vida possível de ser vivida.

Também nesse contexto e cenários da pesquisa muitas coisas pareceram incapturáveis, seja pela retina (ainda que se tratasse de fotografias), seja pela escrita: tempos e espaços outros, vidas outras. Uma diferença pulsante que convoca a "outrar" (Simoni, Moschen, 2012, p. 181): "encontrar fronteiras em movimento, a estranheza de contornos fluídos" que a todo tempo instigam, desestabilizam certezas e nos movem em direção a estar em outro lugar. "Outrar significa suspender o olhar que parte do mesmo, deslocando-se para a fronteira vertiginosa do estranhamento". Modos outros de dormir, comer, trabalhar, cuidar do corpo; de ser família, de construir abrigos, de fazer dinheiro; outros modos, enfim, de inventar a vida nas suas (im)possibilidades. Outrar como exercício etnográfico de conhecer modos de vida no mundo da rua, estranhando o familiar e aproximando o estranho.

\section{AS HISTÓRIAS, SEUS PROTAGONISTAS E SEUS TERRITÓRIOS}

Gregório é um homem pardo, magro, alto; usa sempre bermuda, camiseta e sandálias tipo havaianas. Tem 45 anos, é solteiro, foi operário da construção civil e hoje é artesão. Chegou há 15 anos no Ceará, para trabalhar numa grande obra no litoral do estado. Quando a obra terminou, foi demitido, mas ficou em Fortaleza, instalando-se na rua há 7 anos. Afirmou não querer voltar para sua terra natal, apesar da saudade que sente da família. Diz que gosta muito de Fortaleza, onde "o povo é hospitaleiro e tem trabalho". Gregório usa um albergue noturno para dormir, quando há vagas. Quando não há, dorme numa praça no centro da cidade. Acha isso muito ruim, pois nessa condição se sente exposto a muitos riscos. 


\section{PSTERACÃO EM}

Maria Teresa Nobre e Irlys Alencar Firmo Barreira

Por causa de um, todos paga. As pessoas têm medo da gente, pensa que é tudo vagabundo, manda a gente trabalhar. Eu tenho trabalho certo, mas tem esse povo que não faz nada, não quer nada, rouba, vive drogado, é marginal e por causa deles, todo mundo paga. Tem que ter um ofício pra ocupar a mente vazia. Mas todos não pensa assim. (Fragmento narrativo registrado em diário de campo)

Gregório vende seu artesanato em madeira, metal e serigrafia em duas praças no centro da cidade. A matéria prima ele geralmente ganha, "mangueando". Manguear é um tipo particular de mendicância, que consiste na arte do convencimento acerca da gravidade da necessidade do pedinte junto ao potencial doador, através de uma retórica, em geral, astuciosa. Difere da mendicância, que não manipula e consiste numa confissão da necessidade do pedinte, menos eficaz do que o mangueio, segundo a avaliação de seus praticantes. Gregório é um bom mangueador e quase sempre consegue o que precisa.

Atualmente tem uma rotina bem demarcada: quando acorda, vai para a sede de uma instituição católica, onde faz um curso. Almoça lá ou num refeitório beneficente num bairro vizinho e segue para fazer e vender seu artesanato nas praças. Depois espera o jantar, uma sopa ou quentinha em uma das praças do centro, onde sempre há algum estouro, outra categoria nativa que funciona como um código entre as pessoas na rua: significa que algo está sendo doado ou ofertado, por alguma instituição religiosa ou filantrópica, como alimentos, roupas, corte de cabelo, etc. Depois, dirigese ao local de dormida. Em tempos bons, paga uma pousada ali no centro mesmo. Diz com orgulho de si mesmo: "Não bebo, não fumo, sou católico, sou profissional. Todos esses anos na rua e não cai na decadência do crime, nem no vício". Gregório faz planos de alugar uma quitinete, comprar uma cama de casal, uma moto e material para o artesanato ou negociar com confecções, quando receber o dinheiro de uma ação trabalhista. Toma banho em lugares pertencentes a serviços públicos ou filantrópicos que frequenta, onde também lava suas roupas. Carrega uma sacola com os apetrechos de trabalho e produtos que vende e uma mochila com seus pertences pessoais. É querido e protegido pelos gestores ou profissionais dos serviços que utiliza, embora seus pares na rua demonstrem reservas: "ele tem muita pose, está sempre enrolando e gosta de aparentar o que não é".

A praça onde Gregório trabalha e às vezes dorme é um grande dormitório a céu aberto da cidade de Fortaleza, onde todas as noites dormem cerca de 70 pessoas, nos bancos, nas marquises das lojas que a circulam, nos monumentos, sobre pedaços de papelão, colchões ou diretamente no chão. Magros e negros em maioria, "marca-lhes o desígnio do lugar nenhum" (Baptista, 1999, p. 97). Cobrem-se com lençóis surrados sobre papelão ou no chão liso, outros dormem descobertos e muitos se agrupam, enfileirando-se, uns ao lado dos outros, lembrando o esquadrinhamento de que fala Foucault (2000), quando se refere à tecnologia disciplinar dos corpos. De manhã cedo, antes das 7:00 horas, rapidamente esses lugares inventados e improvisados como dormida se desfazem como que se preparando para a abertura do comércio e para a circulação das pessoas. Os que dormem nas marquises das lojas recolhem seus pertencem e não deixam vestígios da sua ocupação, salvo um ou outro colchão que fica por ali, amarrado em cima de orelhões, em brechas das paredes entre os prédios, pendurados em árvores ou embaixo dos bancos, onde também os flanelinhas guardam baldes e outros instrumentos de trabalho. Durante todo o dia, a praça continua a abrigar em seus bancos pessoas que moram ou vivem na rua que por ali continuam dormindo sobre os bancos ou nos monumentos, porém em quantidade significativamente menor do que no início da manhã.

A vida da praça ao longo do dia é intensa. Inúmeros transeuntes, comerciários que esperam a hora da entrada no trabalho, vendedores de lanches, carroceiros e catadores de material reciclável; grupos de repentistas, hip hop e outros cantores, atores e dançarinos, ciganas que leem mãos e pedem trocados, artistas latino-americanos com seus trajes típicos que tocam e cantam, pessoas que imitam estátuas, fazem performances e recolhem moedas; vendedores de loterias, profissionais da saúde em campanhas, vendedores e operadores de telefonia celular, ambulantes e consumidores de todos os tipos, pedintes entre os quais muitos mutilados ou portadores de deficiência, flanelinhas e controladores de Zona Azul (áreas regulamentadas de estacionamento); africanos e sírios refugiados, profissionais do sexo, pregadores da fé e tantos outras pessoas que por ali transitam e a fazem babel e cosmopolita.

Muitas pessoas passam todo o dia ali, dormindo, vadiando desapercebidas ou despercebidas, ou inventando jeitos de fazer dinheiro. Na frágil e transitória demarcação de território, os lugares de dormida são facilmente ocupados de forma alternada, fazendo da provisoriedade a marca mais constante da vida vivida nas ruas. Gregório, ao integrar esse cenário, junta-se a outros companheiros de vida na rua, produzindo uma inflexão na vida da praça: a vida com suas urgências cotidianas modulando simultaneamente percursos e conquistas diárias intermitentes e singulares ao mundo da rua.

Do outro lado do oceano, em uma das portas de uma grande estação de metrô, em Lisboa, pelo lado exterior que dá acesso a uma avenida importante, vive Vicente. Tem 45 anos, branco, muito alto, natural de Lisboa, divorciado. Ali, na 


\section{W'INTERACÃO EM ET. PSICOLOGIA}

porta larga e alta, fez sua casa: dois colchões, algumas sacolas de roupa, um guarda-chuva e dois cobertores grossos, fazem a mobília. Debaixo dos cobertores, entre as sacolas e os colchões, guarda sua biblioteca: cerca de 10 livros sobre romances policiais e tramas históricas que ganha dos voluntários ou de outros amigos e troca-os, após lê-los. "Hoje meu lema é: Como quando tem, durmo quando posso, leio quando há. Às vezes me esqueço do mundo lendo as histórias, as tramas, as armadilhas, a imaginar como tudo vai se desenrolar".

Vicente gosta de cinema e às vezes assiste filmes na TV da estação. Sua história foi assim narrada: há 20 anos, tinha trabalho, mulher e filhos. Viciou-se em heroína e outras drogas, perdeu o emprego, divorciou-se, cometeu um crime e foi preso. Quando saiu da prisão, passou a viver nas ruas, há mais de 7 anos. Tentou suicídio 3 vezes e na última tentativa procurou ajuda de um grupo religioso que o encaminhou para uma comunidade terapêutica. Depois de um ano, saiu e voltou para a rua. Seus pais e irmãos moram em Lisboa e na casa deles ainda há um quarto seu, mas disse não querer viver às custas da família. "Estou aqui por opção, pronto! Não é fácil, tem que ter estômago para aguentar certas coisas", diz, relatando episódios de discriminação e preconceito por parte dos transeuntes e turistas. "A discriminação é o que mais dói na vida da rua". Vicente não usa os albergues noturnos, não gosta das companhias e das regras. "Melhor estar aqui e ser livre, fazer o que quero, pronto!".

A rotina de Vicente se processa da seguinte forma: quando acorda, por volta das 8:00 horas, toma um café na estação, depois vai à livraria. As vendedoras o deixam folhear os livros e carregar o celular. Usa um balneário público para tomar banho e se barbear. Lava roupa na casa da irmã, embora se apresente às vezes um pouco sujo e descuidado. Durante o dia, come o que sobrou do jantar que lhe dão os grupos de voluntários que por ali distribuem alimentos todas as noites. Tem problemas pulmonares devido ao fumo, que substitui as drogas mais pesadas, e quando adoece é atendido por uma ONG de médicos, que por ali passa quase todas as noites. Na porta da estação que se encontra ao lado da sua, há sempre outra pessoa sem abrigo. Inicialmente, era um português de Bragança, agricultor à procura de trabalho, depois um jovem, também português, que teve problemas no albergue noturno que frequentava, por ser homossexual. Quando chove vão dormir debaixo de uma marquise do outro lado da rua, para onde levam, temporariamente, tudo o que têm.

Os três se referiram à morada na rua como um lugar bom. "É como se fosse nossa casa. Temos nosso canto, sempre um de nós fica por perto para olhar nossas coisas e cá estamos seguros. Moramos perto do centro, há muitos artistas na rua, música, então tudo isso é bom!" Vicente nunca mendiga, acha indigno e também não se preocupa em "inventar dinheiro". Quando do nosso último encontro, disse que recentemente havia sido pego pela polícia roubando umas frutas. A sua irmã pagou uma fiança de 200 euros para soltá-lo. Vicente diz que talvez um dia vá embora, quando sanar suas pendências com a Justiça, que julga já pagas: "a condenação é consciência da pessoa".

A estação onde Vicente inventou sua morada de poucos bens situa-se em uma região de Lisboa que vive um intenso processo de gentrificação, através do qual certos espaços da cidade são eleitos como centralidade pela iniciativa pública ou privada, estabelecendo-se neles novos empreendimentos econômicos. Como discutido por Leite (2007), inicialmente a expressão foi usada para caracterizar a intervenção urbana visando a reabilitação residencial de bairros centrais das cidades, passando depois a designar também a renovação urbana em larga escala, visando à higienização dos centros urbanos, tornando-os limpos, seguros e atrativos comercialmente. A ação configura-se como estratégia política, voltada às demandas por segurança e proteção, sem considerar a população residente na área e tomando o patrimônio histórico e cultural ali situado como mera mercadoria. Assim, para além de buscar otimizar o potencial de investimentos econômicos e culturais em áreas centrais, a gentrificação "afirma dimensões simbólicas de poder por meio de inscrições urbanísticas e arquitetônicas que representem visualmente valores e visões de mundo de uma nova camada social que busca apropriar-se de certos espaços da cidade" (Leite, 2007, p. 63).

No espaço gentrificado de Lisboa onde Vicente vive, antigos moradores, na maioria idosos, com hábitos arraigados e longas histórias, habitam pequenas casas ou sobrados, há muitas décadas, hoje disputados pela especulação imobiliária, dado o seu elevado potencial de comercialização para turistas e novos moradores. Longas histórias podem ser ouvidas no entorno da estação, nas pequenas ruas estreitas, ladeiras e becos tortuosos, onde as pessoas falam da ameaça da perda desse lugar onde sempre viveram. O aumento exorbitante dos aluguéis, as taxas e impostos elevados cobrados pela Câmara de Lisboa, os assombra na incerteza do amanhã, apontando a transformação das centralidades na Área Metropolitana de Lisboa (Xerez, 2008). Pequenos pontos comerciais e muitos operários que residiam no centro da cidade e em alguns dos seus bairros históricos foram deslocados para outras regiões mais afastadas. Novos residentes com poder aquisitivo mais elevado e estilos de vida que valorizam o ambiente urbano do centro das cidades, tornou esses bairros atrativos e caros. Casas e outros edifícios antigos e degradados, mas com 


\section{INTERACÃO EM LF PSICOLOGIA}

elevado valor arquitetônico, são reformados, passando a onerar sua aquisição e o valor dos aluguéis (Xerez, 2008).

Dentro da estação, o movimento é intenso. Muitos passageiros estrangeiros, imigrantes ou turistas e portugueses nas suas lidas diárias, sempre apressados, a correr para pegar o metrô ou os trens suburbanos e de longo curso, parecem afirmar que tudo é transitório e fugaz naquele espaço. Os poucos e desconfortáveis bancos da estação impedem que ali se possa dormir ou permanecer por muito tempo. Seguranças fazem a ronda de maneira pouco ostensiva, mas contínua, impedindo a permanência de quem ali quer fazer morada: é terminantemente proibido a um semabrigo instalar-se, mesmo nos períodos mais frios ou nos dias de chuva, ainda que seja apenas por uma noite. As portas externas da estação, ao contrário, os acolhem, assim como os becos e ruelas próximas dali, onde se pode encontrar dezenas de pessoas sem abrigo, a dormir nos bancos, nas marquises, em outras estações de metrô próximas dali, mendigando, "arrumando carros" (o que equivale ao ofício de flanelinha no Brasil) ou conversando, tentando ganhar alguns trocados de turistas e transeuntes. 0 dentro e o fora da estação contam histórias diferentes, entre a permanência e a provisoriedade, cada vez mais próximas uma da outra, pela nova cara que o bairro adquire, marcado pela efemeridade do turismo com suas ofertas de aluguéis temporários, rotas de visitas e circulação de pessoas, transeuntes e novos moradores.

Vicente habita esse espaço que, para quase todos que dele fazem uso, constitui um não lugar (Augé, 2005), uma passagem, sem nenhuma relação de identificação. Para Vicente, entretanto, como para tantos outros sem abrigo que ali moram, é um lugar próprio. Um lugar inventado que lhes dá abrigo e segurança: um canto, uma casa sem paredes e sem muros, na qual a frágil permanência não demonstra apenas uma norma desviante. Para muitos, a rua é também um lugar vivido como espaço de liberdade, que lhes permite escapar das normas das instituições de acolhimento que abominam e onde é possível escolher companhias, cultivar gostos e viver conforme o próprio tempo.

\section{MULTIPLICIDADES E REINVENÇÕES NO MUNDO DA RUA}

As pessoas que vivem nas e das ruas têm razões diferentes para estarem nesta condição. Para Gregório, o desemprego, para Vicente, a droga, o crime e a prisão, situações comuns a muitos outros. De fato, múltiplas são as razões que levam as pessoas a viver na/da rua, sendo todas elas expressivas da relação com um processo de perda ou ruptura (Escorel, 1999; Frangella, 2009): uma tragédia, um acontecimento dramático, crítico ou um dano às vezes irremediável. Para muitos que encontramos, essa ruptura não está em um lugar do passado, ela é reatualizada no cotidiano, produz outros rompimentos e, simultaneamente, novos trajetos, tessituras de outras rotas, percursos e caminhos: a busca ou invenção de um lugar para dormir; a fome saciada pela filantropia, sempre diária e insuficiente; a criação de uma rotina, indicando a atribuição de normas impostas a si e por si mesmo, mas que também respondem às demandas sociais do tempo dos outros; as relações com os pares, com os que passam entorno e com as instituições, oscilantes entre a cordialidade e o desafeto, a caridade e discriminação, a parceria e a hostilidade, a confiança e a desconfiança; os cuidados com o corpo na sua relação com a cidade e no acesso a espaços públicos; as variações entre a moral e a ética.

A experiência de morar ou viver nas e das ruas de modo inventivo e insurgente lembra a estética da existência, defendida por Foucault (1985), presente na busca errante por um estilo de vida insubordinado à moral e às regras que os assujeitam, numa tentativa de governar-se a si mesmos, como sugere a história de Vicente. Outros, ao contrário, como Gregório, vivem um processo de maior captura pelas lógicas instituídas (Deleuze, 2013), buscando sempre se guiar pela preservação de uma boa imagem de si diante dos outros. Neste sentido, chamam atenção as diferentes maneiras de pautar a vida entre o legal e o legítimo. Vangloriar-se do próprio comportamento, da atenção à moral, aos pilares que definem a normalidade, o prescrito e o proscrito socialmente, a via da reprodução das instituições e dos modos de vida desejáveis, porque não desviantes, são narrativas comuns encontradas nas ruas, que constroem imagens positivas de si: ter religião, ser trabalhador, não ter vícios, andar sempre na linha. Interceptando essas práticas e imagens, a astúcia favorece a manipulação de muitas artimanhas, que dão acesso ao reconhecimento social junto às instituições. Assim, é interessante notar o modo como pessoas que vivem nas ruas não se percebem como parte de uma categoria totalizadora. A separação entre drogados, ladrões ou os que não fazem nada, como Gregório classifica seus pares, atesta a existência de representações baseadas em critérios de moralidade. 0 mundo da rua tem seus códigos de inclusão e exclusão!

Muitos, porém, como Vicente, não trabalham, são usuários de drogas, são ex-presidiários, acham indigno mendigar, mas consideram legítimo cometer pequenos furtos, para sanar certas necessidades, revelando outros critérios de julgamento definidos pelo que poderia ser nomeado por ética do mundo da rua, baseada no império da necessidade e recusa relativa de regras consideradas impositivas. São respeitados pelos seus pares, com quem 
têm relações amistosas de reciprocidade, dividem o espaço, a discriminação e as incertezas, driblam a solidão. Esses diferentes modos de obediência às normas sociais, ou à própria consciência e sentido do que seja o justo e o bom, revelam diferentes códigos éticos e morais, produzidos e adotados por quem vive nas e das ruas, estreitando as relações entre a norma e o desvio, uma linha fronteiriça entre a legalidade e ilegalidade (Telles, 2010).

O culto ao trabalho, por alguns, e ao ócio, por outros, também demarcam diferenças na escala das necessidades e desejos, de pessoas que vivem nas e das ruas. Nas narrativas ouvidas neste estudo, que tomamos como emblemáticas, esses movimentos, embora opostos, podem ser vistos como não antagônicos, pois que ancorados em processos de criação: a arte, para Gregório; a literatura, para Vicente. Essa criação e fruição os levam ao nomadismo: Gregório precisa andarilhar para vender seu artesanato e manguear sua matéria prima; Gregório é um andarilho que não sai do lugar, a viajar por histórias de armadilhas, intrigas e terror, enredos da sua própria vida, narrados por outros. Afınal, pensamos e criamos, sejam quais forem os modos de expressão, porque algo em nossas vidas nos força a fazê-lo, porque a vida mesma pede passagem, especialmente quando são vividos processos de desterritorialização, crises e perda de referências (Rolnik, 2015).

A ruptura que se produziu nessas histórias e que está na base das idas e permanências na rua, deslocam referências de territórios anteriores onde a dor por essa falta de lugar pede passagem, exigindo a reinvenção de si e dos modos de vida, na rua que os acolheu. Reinvenção que sugere modos de improvisação, aproveitamento de situações e capacidade de transformar carências em recursos provisórios.

Gregório produz artesanato, vive disso e para isso, todo o seu dia, andanças e investidas estão voltados para o processo de criação e comercialização da sua arte, que lhe garante a reprodução da vida. Vicente consome livros que o permitem criar outro mundo, Ihe dão prazer, aguçam sua curiosidade, sua imaginação e fantasia, Ihes fazem sentir temores e alegrias. A vida que pede passagem encontrou nessas formas de expressão um novo lugar no mundo da rua.

Encontramos em Lisboa alguns que afirmaram estar na rua por opção, como Vicente, que mantém preservados os vínculos familiares. Em Fortaleza, como no restante do Brasil, é mais raro encontrar essa situação. As pessoas que moram ou vivem nas ruas têm, em geral, laços rompidos ou fragilizados com a família (Brasil, 2009), situação que também acontece em Portugal (ENIPSA, 2009). Em ambas as cidades, porém, ouvimos pessoas afirmarem que, na rua, sentem-se livres, e é interessante observar a ambiguidade de um sentimento de quem parece estar na fronteira e com isso barganha valores e negociações, eufemizando a situação de penúria compensada no discurso de afirmação de liberdade. Tudo se passa como se a situação de miséria produzisse o consolo de que poderia ser pior, atenuando os efeitos que se produzem e reproduzem cotidianamente na vida social: a condição de destituição metamorfoseada em opção. A rua teria, assim, Ihes permitido a criação de outros territórios, materiais e simbólicos.

Nessa perspectiva, o território não representa um limite geográfico, mas também e, sobretudo, os acréscimos que os homens impuseram a esses sistemas, como propõe Milton Santos (2002): o território reúne a materialidade do espaço e a vida que o anima. As pessoas que perderam seus territórios materiais, referenciados principalmente pela moradia, criaram novos territórios existenciais, no seio do qual se sentem em casa (Guattari \& Rolnik, 2007), sublimando a condição de efemeridade, no sentido usado por Bourdieu (1997).

As buscas impostas pelas rupturas que produziram o choque da desterritorialização - a perda da segurança, da estabilidade financeira e emocional, de afetos, de lugares físicos e simbólicos - não reptresentaram, para pessoas que vivem ou moram nas ruas, um resgate do que foi perdido, mas a construção de um território existencial a partir do qual buscam ressignificar a vida (Guattari \& Rolnik, 2000) na condição fronteiriça do efêmero, provisório e incerto de cada dia.

O território é sinônimo de apropriação, de subjetivação fechada sobre si mesma. Ele é o conjunto dos projetos e das representações nos quais vai desembocar, pragmaticamente, toda uma serie de comportamentos, de investimentos, nos tempos e nos espaços sociais, culturais, estéticos, cognitivos. A reterritorialização consistirá numa tentativa de composição de um território engajado num processo desterritorializante. (Guattari \& Rolnik, 2000, p. 323).

Desterritorializados dos espaços e lugares que tinham e sobre os quais haviam construído suas referências, produzem outras territorializações não situadas, porque desviantes e, por isso, sempre abertas, em processo. Vidas que traçam mapas destoantes, feitos de linhas tortuosas e de costuras alinhavadas, tecidas na incerteza do aqui e do agora, mas fincadas em outros lugares onde foi e é possível aportar. Trajetórias que falam de modos possíveis de "cuidado de si", construídos nas relações com os outros e como efeito de relações de poder (Foucault, 1997) que se incrustam, se movem e deixam suas marcas nas suas histórias e nos seus percursos, contra as quais se rebelam, seja silenciosamente, através da recusa, seja ruidosamente, através do desvio. Modos de reinvenção de si que subvertem, 


\section{-4: INTERACÃO EM LF PSICOLOGIA}

muitas vezes, o uso dos espaços e do tempo, a lógica da produção e do consumo, a utilidade dos corpos.

\section{CONSIDERAÇÕES FINAIS}

O fenômeno dos homeless como categoria mais ampla, que abrange as classificações dos sem-abrigo, sem-teto e pessoas em situação de rua, tem expressividade mundial, associando-se ao avanço do capitalismo, das guerras, da fome, do aumento do desemprego e do recrudescimento das intolerâncias religiosas. Entretanto, na relação entre a macro e a micropolítica, transversalizando esse quadro, tanto em Fortaleza quanto em Lisboa, observa-se a existência de pessoas praticantes dos espaços (Certeau, 2005) que surpreendem pela habilidade em fazer uso deles, recriando modos de viver em novos territórios materiais e existenciais.

Apesar das diferenças geográficas, climáticas e culturais, o que foi encontrado na pesquisa, para além das histórias de Gregório, em Fortaleza, e de Vicente, em Lisboa, aqui mencionadas, possibilita traçar alguns paralelos sobre 0 mundo da rua e os modos de vida nas duas cidades. Locais ocupados à noite (as praças do centro da cidade, prédios abandonados e marquises de lojas, em Fortaleza, e as estações de metrô e trem ou fluviais, marquises de lojas e escadarias de igrejas, em Lisboa) se transformam em amplos dormitórios ao ar livre, que se desfazem rapidamente quando a circulação de transeuntes e as atividades do comércio e turismo têm início pela manhã, mostrando como os espaços que foram privatizados durante à noite voltam à condição de espaços públicos durante o dia. Mas, apesar desse traço dominante, as situações são variáveis. Muitos constroem suportes que se assemelham a verdadeiras casas, aproveitando os restos do lixo descartado nesses e em outros lugares. Em Fortaleza, inúmeros "carregam a casa nas costas", em bolsas, sacos ou mochilas nas quais levam tudo o que têm. Em Lisboa, esse quadro é amenizado pela existência de armários dispostos em alguns pontos da cidade para a guarda de pertences dos sem-abrigo, o que, associado ao acesso a água potável em bebedouros na rua e a existência de balneários públicos, marca uma diferença significativa no direito à cidade.

Crianças em situação de rua no Brasil ${ }^{2}$, a quantidade de imigrantes em Lisboa (sobretudo do leste europeu e das antigas colônias africanas) e as diferentes políticas frente ao consumo da droga - proibicionista no Brasil e não proibicionista em Portugal -, também marcam diferenças entre as duas situações expostas. Há muitos não documentados, em ambas as situações, com graves consequências sobre a mobilidade e o acesso a serviços públicos e ao trabalho. A vida é tocada de muitas maneiras, entre o trabalho sempre precário, a mendicância e o manguear, a frágil conquista de direitos e a noção de caridade. Trata-se de valores que oscilam entre o público e o privado, entre os quais compaixão e preconceito se entrelaçam. Nos modos de suprir necessidades e desejos, se entrecruzam noções de lei, direitos e deveres, cidadania e justiça construídos nas tênues fronteiras entre legal e ilegal. Os nossos protagonistas, Gregório e Vicente, estão enredados nas aproximações ou diferenças com os demais, nessa construção de inúmeras possibilidades de vida no mundo da rua.

Vemos, assim, como a capacidade de resistir aos jogos de poder-saber que também engendram afetos é inseparável da possibilidade de composição com forças inéditas e de mudança que a vida pode alcançar (Maciel Júnior, 2014), significando aberturas, embora estreitas, de criar o mundo e a si mesmo, num movimento indissociável. Retomando Foucault (1985), para concluir essa incursão pelo mundo da rua, reafirmamos a ideia da reinvenção de si como prática de subjetivação que cria novos modos possíveis de vida, como que produzindo uma torção na precariedade das condições materiais de existência, implicando o movimento correlato de reinvenção do mundo (Kastrup, 2001). Essas vidas inventadas e amalgamadas nas histórias das cidades onde habitam mostram como as pessoas conseguem caminhar por entre os nós das redes dos jogos de poder que capturam a vida através da assimilação e reprodução da moral, dos códigos e valores ou da norma, criando possibilidades de vida não restritas exclusivamente às interdições e ao assujeitamento.

A diversidade desses modos de viver extrapola a noção de direito à cidade como acesso ao espaço público e a nele transitar ou dele usufruir, remetendo-a a um sentido mais amplo, como o próprio direito à vida (Lefebvre, 2001). A ocupação do espaço para dormir ou morar, a circulação pela cidade, os itinerários institucionais e as rotinas subvertem os usos instituídos, com a reinvenção das práticas corporais nos cuidados de higiene, abrigo, alimentação, enquanto o trabalho e o ócio concorrem em significado e lugar. Rupturas várias estão na base do processo de ida para as ruas e de permanência nelas, evidenciando diferenças geracionais, raciais e de gênero, de escolaridade, nível socioeconômico, de dores, culturas e tradições, produzindo o choque da desterritorialização e impondo a busca por outros caminhos. Novas territorializações assentadas em práticas que fazem das ruas um lugar de possibilidades. Trata-se da invenção de novos territórios materiais e existenciais, o que implica na apropriação peculiar do mundo e de si, escapando à imagem exclusiva da privação, da ausência, da carência, da vitimização ou da culpabilidade. 


\section{WINTERACÃO EM ET. PSICOLOGIA}

Nesse sentido põem-se novas questões para se repensar os polos sobre os quais se assentam as representações das pessoas que vivem nas/das ruas, nas duas cidades. A pesquisa em ambas permitiu repensar categorias dicotômicas e excludentes, repondo a importância de se examinar a diversidade e a complexidade do mundo da rua. $A$ ideia de refletir sobre o mundo da rua não implica uma romantização da liberdade e tampouco o desconhecimento da situação de risco a que estão expostos os contingentes que habitam as ruas e têm suas vidas quase sempre encurtadas. Mostrar o processo de recriação nas extremidades supõe, por outro lado, observar os diferentes ângulos da questão que estão para além de opostos com os quais pensamos os que se situam fora das categorias convencionais de observação. Trata-se de um desafio tanto para as políticas públicas como para as ciências humanas e sociais.

\section{CONTRIBUIÇÃO DE CADA AUTOR}

M.T.N. e I.A.F.B. participaram da conceitualização, metodologia do artigo e redação final (revisão e edição do texto). M.T.N. realizou a investigação e foi responsável pela redação inicial do artigo (rascunho). I.A.F.B. supervisionou as atividades de planejamento e execução da pesquisa em Fortaleza

\section{DECLARAÇÃO DE CONFLITOS DE INTERESSES}

As autoras declaram que não há conflitos de interesses no presente artigo.

\section{AGRADECIMENTOS}

As autoras agradecem ao Prof. Dr. José Machado Pais, supervisor de Pós-Doutorado da primeira autora, no ICSULisboa, pelas relevantes contribuições ao desenvolvimento do trabalho de campo em Lisboa e pelas reflexões teóricometodológicas sobre o tema da pesquisa.

\section{REFERÊNCIAS}

Augé, M. (2005). Não lugares: Introdução a uma antropologia da sobremodernidade. Lisboa: 90 Graus.

Baptista, L. A. (1999). A cidade dos sábios: Reflexões sobre a dinâmica social nas grandes cidades. São Paulo: Summus.

Bourdieu, P. (Org.) (2012). A miséria do mundo. (9a. edição) Petrópolis: Vozes.

Bourdieu, P. (1997). Meditações pascalianas. Rio de Janeiro: Bertrand Brasil.
Brasil (1990). Presidência da República. Lei 8.069 de 13 de julho de 1990. Dispõe sobre o Estatuto da Criança e do Adolescente e dá outras providências. http:// www.planalto.gov.br/Ccivil_03/leis/L8069.htm

Brasil (2009). Presidência da República. Decreto-Lei 7.053/2009. Institui a Política Nacional para a População em Situação de Rua e seu Comitê Intersetorial de Acompanhamento e Monitoramento e dá outras providências. http://www.planalto.gov.br/ccivil_03/ _Ato2007-2010/2009/Decreto/D7053.htm

Certeau, M. (1984/2005). A invenção do cotidiano: As artes de fazer. v. 1. Petrópolis: Vozes.

Da Matta, R. (1985/2003). A casa \& a rua: Espaço, cidadania, mulher e morte no Brasil. (4 ${ }^{\mathrm{a}}$. ed.) Rio de Janeiro: Ed. Guanabara Koogan.

Deleuze, G. (1992/2013). Conversações. São Paulo: Editora 34.

ENIPSIA. Estratégia Nacional para Integração de Pessoas Sem Abrigo: Prevenção, intervenção e acompanhamento (2009-2015). http://www.seg-social.pt/documents/ 10152/13334/enipsa_2009_2015

Escorel, S. (1999). Vidas ao léu: Trajetórias de exclusão social. Rio de Janeiro, Fiocruz.

Foucault, M. (1975/2000). Vigiar e punir. (23a. ed). Rio de Janeiro: Vozes.

Foucault, M. (1985). História da sexualidade 3: O cuidado de si. Rio de Janeiro: Ed. Graal.

Foucault, M. (1997). Subjetividade e verdade. In Foucault, M. (1997) Resumo dos Cursos do Collège de France (19701982). Rio de Janeiro: Jorge Zahar Editor.

Foucault, M. (2003). Estratégia, Poder-Saber. Coleção Ditos e Escritos, v.4. Rio de Janeiro: Forense Universitária.

Frangella, S. M. (2009). Corpos Urbanos Errantes: Uma etnografia da corporalidade de moradores de rua em São Paulo. São Paulo: AnnaBlume/Fapesp.

Goldman, M. (2003). Os tambores dos mortos e os tambores dos vivos. Etnografia, antropologia e política em Ilhéus, Bahia. Revista de Antropologia, 46(2), 423-444. https:// dx.doi.org/10.1590/S0034-77012003000200012

Gonçalves, M. J. \& Sani, A. I. (2013) Instrumentos jurídicos de proteção às crianças: do passado ao presente. Cadernos CES. http://journals.openedition.org/eces/1728\#tocto1n3

Guattari, F. \& Rolnik, S. (1986/2000). Micropolítica: Cartografias do desejo. Petrópolis: Vozes.

Habermas, J. (1984). Mudança estrutural da esfera pública. Rio de Janeiro: Tempo Brasileiro.

Kastrup, V. (2001). Aprendizagem, arte e invenção. Psicologia em Estudo, 6(1), 17-27. http://dx.doi.org/10.1590/S141373722001000100003 . 


\section{-4: INTERACÃO EM IF PSICOLOGIA}

Lapassade, G. (1996/2005). As microssociologias. Brasília: Liber Livro Editora.

Lefebvre, H. (2001). O direito à cidade. São Paulo: Centauro.

Leite, R. P. (2007). Contra-usos da cidade: Lugares e espaços públicos na experiência urbana contemporânea (2a. ed.). Campinas: Editora da UNICAMP; Aracaju: Editora UFS.

Maciel Júnior, A. (2014). Resistência e prática de si em Foucault. Trivium Estudos Interdisciplinares. Psicanálise e Cultura, 6 (1), 1-8. https://www.uva.br/trivium/edicoes/ edicao-i-ano-vi/artigos-tematicos/artigo-tematico-1.pdf

Magnani J. G. C. (2009). Etnografia como prática e experiência. Horizontes Antropológicos, 15(32), 129-156. https://dx.doi.org/10.1590/S0104-71832009000200006

Pais, J. M. (2015). Deambulações cotidianas: A emergência de um método na observação dos sem teto. Estudos de Sociologia. 1 (21), 35-72.

Pina-Cabral, J.\& Durão, S. (Org) (2013). Exercícios de escrita etnográfica. Lisboa numa tarde de julho de 2012. ICS Estudos e Relatórios. Editora ICS: Lisboa.

Rio, J. (1910/2013). A alma encantadora das ruas: Crônicas. São Paulo: Companhia das Letras.

Rolnik, S (2015). Geopolítica da cafetinagem. Territórios de Filosofia. https://territoriosdefilosofia.wordpress.com/ 2015/05/20/geopolitica-da-cafetinagem-suely-rolnik/
Santos, M. (2002). O retorno do território. In: Santos, M. (Org). Território, globalização e fragmentação. (5a edição). São Paulo: Anablume/Hucitec/Anpur.

Sato, L. \& Souza, M. P. R. (2001). Contribuindo para desvelar a complexidade do cotidiano através da pesquisa etnográfica em psicologia. Psicologia USP, 12, (2), 29-47 http://dx.doi.org/10.1590/S0103-65642001000200003

Simoni, A. C. R. \& Mosschen, S. (2012). Outrar. In: Fonseca, T. M. G., Nascimento, M. L.; Maraschin, C. (Orgs.). Pesquisar na diferença: Um abedecedário. Porto Alegre: Sulina.

Telles, Vera (2010). A cidade nas fronteiras do legal e ilegal. São Paulo: Fino Traço

Xerez, R. (2008). Dinâmicas do Território: Centralidades e gentrificação na área metropolitana de Lisboa. Anais do VI Congresso Português de Sociologia: saberes e práticas, Universidade Nova de Lisboa, Lisboa, Portugal.

Recebido em: 29/10/2017 Primeira decisão editorial em: 17/01/2018 Aceito em: 14/03/2018

\footnotetext{
10 trabalho de campo foi realizado pela primeira autora deste artigo em estágio de Pós-Doutorado no Programa de Pós-Graduação em Sociologia da Universidade Federal do Ceará (UFC) sob supervisão da segunda autora e do Prof. José Machado Paz, no ICS - Instituto de Ciências Sociais da Universidade de Lisboa.

2 Brasil e Portugal têm legislações específicas de proteção à criança e ao adolescente: o Estatuto da Criança e do Adolescente (ECA), de 1990, no Brasil e em Portugal, a Lei de Proteção das Crianças e Jovens em Perigo, de 1999, em vigor desde 2001 . A legislação portuguesa dispõe sobre mecanismos reguladores que permitem a intervenção social por parte do Estado e da comunidade, em situações onde as crianças e adolescentes encontram-se em perigo ou carenciados de proteção. (Gonçalves \& Sani, 2013). O ECA, no Brasil, é uma legislação mais abrangente, que dispõe sobre a proteção integral a todas as crianças e adolescentes, indiscriminadamente e não apenas aquelas em situação de risco, embora a estas seja dedicada atenção especial (Brasil, 1990). Durante a pesquisa não encontramos crianças sem abrigo em Portugal (sem teto ou sem casa), nem casais com filhos pequenos ou filhos adolescentes nesta condição. Esse dado sugere uma presença mais intervencionista e protecionista do Estado Português com relação às crianças em situação de rua do que observamos no Brasil, onde não é raro encontrar famílias inteiras vivendo nas ruas ou mendigando. Esse é um dado relevante a ser melhor investigado em pesquisas futuras.
} 